\title{
Listening as Religious Practice (Part Two) - Exploring Qualitative Data from an Empirical Study of the Cultural Habits of Music Fans
}

\section{CLIVE MARSH \& VAUGHAN S. ROBERTS}

\begin{abstract}
This article analyses quantitative data from responses to open questions addressed by 231 musicusers in a 2009-10 survey. By coding and quantifying the data provided, the analysis enables the construction of four 'acoustic axes' (uplift-relax, inspiration-memory, energy-calm, joy/happiness-sad/sadness) which make direct use of respondent-initiated terminology, and which enable a means of mapping the activity which occurs for listeners in the affective space created in the listening process. Use of these axes in turn suggests, at a second level of analysis and interpretation, the construction of a musical-spiritual 'social imaginary' (Taylor) to grasp how music is being used and understood by the music-users themselves with respect to their selfunderstanding and life-commitments. It is concluded that whilst music-use cannot be termed religious/a religion or a form of spirituality in any direct or simplistic sense, there is evidence here of the seriousness and intensity with which listeners make use of their listening practices in the activity of meaning-making.
\end{abstract}

\section{Keywords}

Music, religion, happiness, identity, memory, social imaginary, spirituality 


\section{Introduction}

In our book Personal Jesus: how popular music shapes our souls (Baker Academic 2012) we drew upon data from a survey of 231 listeners to music. We have followed that up with two articles which examine this research data in greater detail. In our first paper we examined the quantitative figures from which asked respondents about their use of popular music and religious affiliation or practice (if any), alongside other aspects of their participation in media and consumption of the arts and popular culture (Marsh and Roberts Habits). We set out our findings under a series

of headings: (a) Types of music listened to; (b) Themes within the music listened to; (c) Means of assessing music; (d) Frequency of listening; (e) Listening in the context of other activities; (f) Male and female responses. On the basis of this analysis, we went on to explore potential interactions between patterns of music consumption, religious practice, and other cultural habits. This present paper builds on that quantitative data by presenting the results of detailed textual analysis of the qualitative material provided by our respondents. The paper investigates the qualitative data to see what conclusions can be drawn from the ways in which our respondents describe their emotional reactions to popular music and what connections there may be, if any, with religious vocabulary and practice.

2. Emotional and Cognitive Activity within a Social Imaginary

In The World in Six Songs Daniel Levitin recounts a conversation with musicologist and neuroscientist Ian Cross in which Cross describes how music developed as a communicative medium optimally adapted for the management of social uncertainty (Levitin 145). This can be at the level of the group or an individual. The importance of this insight is borne out within our own research, and connects directly with Charles Taylor's use of the concept of 'social imaginary.' Taylor understands this term as the ways in which people 'imagine their social 
existence, how they fit together with others, how things go on between them and their fellows, the expectations which are normally met, and the deeper normative notions and images which underlie those expectations' (Taylor 171). Taylor speaks of 'social imaginary' rather than 'social theory' for three reasons: i) he wants to focus on ordinary people's handling of their surroundings; ii) relatively few people theorize; iii) it is important to identify and explore common understandings which are widely shared (171-2). This approach coheres with what we are attempting in our exploration of the reception and use of music.

Both of these aspects of Taylor's stance - the connectedness and depth of everyday social experience, and the concrete/practical as opposed to the theoretical - are evident in insights offered by our respondents. One participant states: 'I like to listen to music that expresses my way of life and emotions/life situation' (R63, hereafter 'R' in each case) whilst another observes, 'Music is there for you no matter what mood you are in, and it can influence your mood' (R68). One notes how music 'creates a common ground to spend time together and keep in touch through suggestions/ updates/ attending gigs' (R84) whilst another recalls that 'Many, many, many of my memories of music are tied up with friends and good times and dancing and festivals' (R72).

Mood is a recurrent theme throughout the responses. In our work, however, we have seen the need to explore exactly how our respondents speak of, use, react to, or shape their moods in relation to the music to which they listen, what the moods (and emotions) do to and for them, what moods and emotions are prominent, and how their expression is located within their everyday life. This article therefore explores some of the key terms our respondents used to describe the ways in which they perceive music to be controlling or affecting their mood. In Personal Jesus we used the data from our survey in a limited way in undertaking a theoretical mapping exercise of how popular music works. We identified four areas of common ground between religion and popular music - embodiment, connectedness, ritual and transcendence (ibid.146-55). This paper digs deeper into the qualitative data to determine what fresh insights 
can be gleaned from music-users' own descriptions of their committed, engaged music-listening habits.

In light of the detailed textual analysis of the responses undertaken, we present the principal words that respondents used to describe the ways in which they use music. We have taken the eleven words which occur most consistently to create four axes around a central hub. The resulting chart, we suggest, configures a form of musical social imaginary which adds depth to the insight that 'music shapes people.' Our findings cohere well with DeNora's description of music as a 'device of social ordering' (DeNora 109-150). The four axes (indicating the number of respondents who used the word without being offered it by us as researchers) are:

(i) Uplift (23)<----------->Relax (29)

(ii) $\quad$ Inspiration (16)<------------>Memory (14)

(iii) $\quad$ Energy (12) <-----------> Calm (13)

(iv) Joy (24), Happiness (27) <-----------> Sad, sadness (13)

The central hub is that of 'mood' (27 mentions) and 'emotion/s' (29). It is possible to refine definitions of such emotions into existing categories (e.g. intense, positive, negative, mixed/conflicting as in North and Hargreaves 136) but our qualitative analysis is guided by the descriptors provided by our participants.

The relationship between these four axes of the resulting musical social imaginary can be represented in this way: 


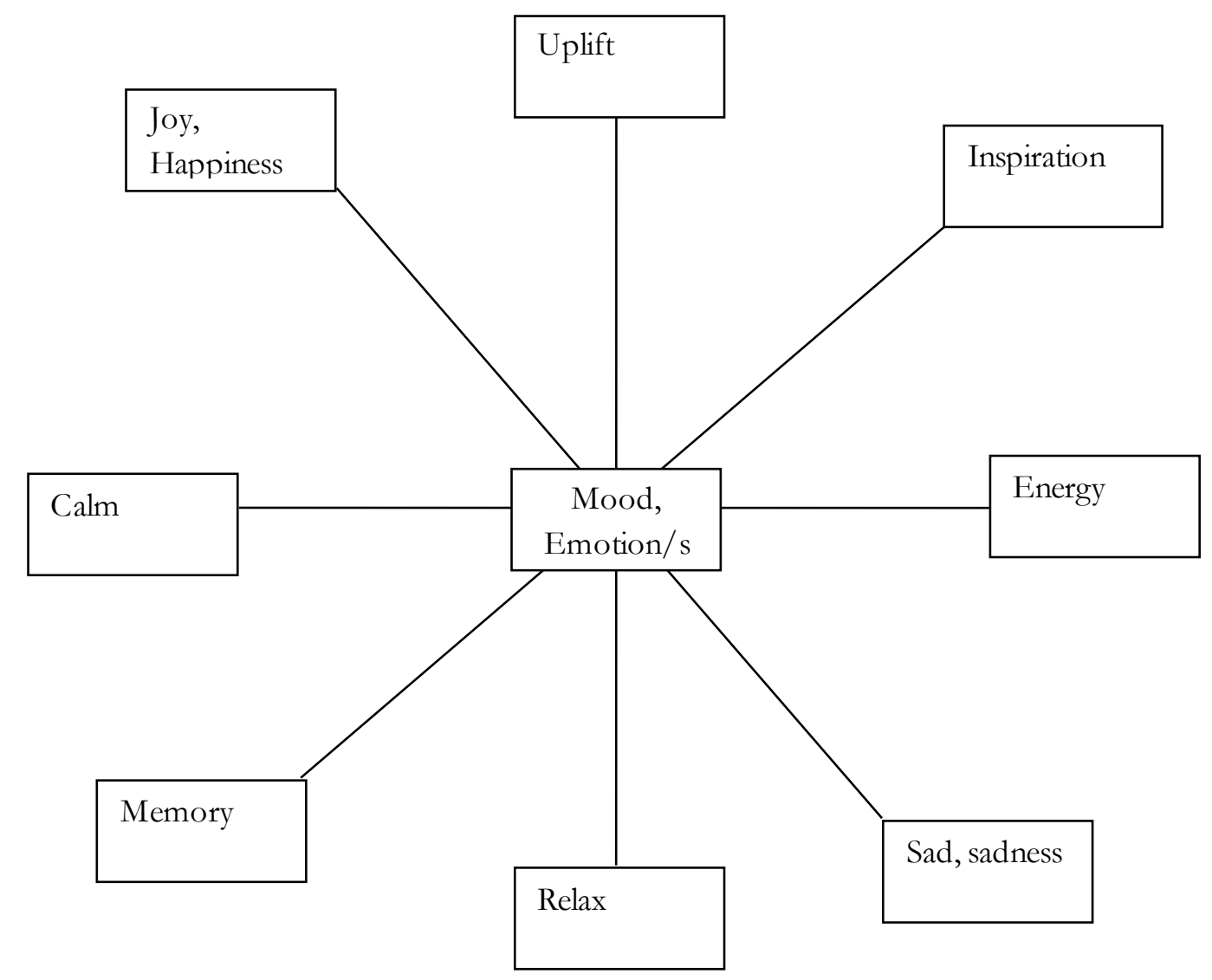

Figure 1: Acoustic Axes from survey data

Given what is evident in these axes, it is clear, and not surprising, that there is both affective and cognitive activity occurring for music-users at the point of reception and use. The importance of emotions in the arts is well-known (Robinson Emotions, Deeper than Reason), the emotional dimensions of music and music reception in particular, even if popular music is not usually the focal point of academic research in this field (Juslin and Sloboda Music and Emotion, Handbook). To that should be added the observation that music is significant within religion as an affective (and effective) vehicle for carrying theology (e.g. Gill 159-202). When put together, those two insights raise the question of what music might therefore carry, and what function it might play, for religious and non-religious people alike, in, through and beyond its affective impact. 
In identifying the emotions experienced, cognitive activity is involved. In reflecting further (even if only for us as researchers) on the emotions and their potential significance and meaning, our respondents provide insights into how the musical social imaginary functions for them. It is these further dimensions we shall now explore by digging deeper into the hub and the acoustic axes we have identified.

\section{Analysis of the Hub and the Four Acoustic Axes}

The hub in our diagram presents the centrality of the affective dimension of musical experience. We had explicitly sought respondents' identifications and descriptions of their emotional response to, and use of, music through our open question 'What words or phrases best describe your emotional experience of music?' Twenty-nine respondents fed back to us the word emotion/s or emotional in their replies, though added twenty-seven references to 'mood.' The four axes to be explored revolve around these references to moods and emotions. The significance of emotional responses to music is starkly expressed by respondents. The following comment vividly illustrates the emotional range of music: 'It's definitely true that emotion and music go hand in hand. I find particular pieces of classic music are needed for stressful days and a good rock anthem on the radio will make me more assertive when driving' (R85). A further respondent states: 'I am helped to relax with music and put back in touch with my emotions' (R157).

Significantly, a number of times the language of emotion is associated with life itself and is used to underscore the importance of music to the listener. Examples of this include: 'I would rather listen to music than watch TV. I wouldn't want to live without music. I find music can help me through emotionally difficult times' (R137); after noting that music covers 'the gamut of emotions', one respondent adds: 'I became a professional musician (teacher of music history and theory) because I didn't want to live even a day without music' (R197); 'without music, I would 
die' (R212). After listing a number of sharply contrasting emotions connected with music, one respondent frames this unsettling conundrum: 'since 1990 I sometimes wonder if I was offered the "choice" between deafness and blindness which I would choose - an impossible decision' (R141).

A voice counter to this, however, should be noted. One respondent suggests an ambiguity regarding music and emotion: 'Usually, music does not make me emotional. It's just a background for what I'm doing. If songs affect me in some way, it is usually because of memories associated with it, happy or sad' (R95). This is important for us to note: the music itself may not produce an emotional response but the memories linked to certain songs do produce emotions of happiness and sadness. It is therefore with respect to the four acoustic axes which revolve around the hub where we should focus our attention.

(i) Uplift <------------> Relax

Twenty three of our respondents made a reference to music being 'uplifting' or providing a sense of 'uplift'. The emotion was often not, however, experienced in isolation. In drawing out these key terms from our data, then, it is important to keep in mind that they are often interconnected. One respondent commenting upon how she is affected by music says that it is: 'Uplifting, moodchanging, relaxing, emotive. Music often marks and becomes associated with events in my life' (R26). Thus, as well as describing music as 'uplifting' such a statement includes references to emotion, relaxation and memory. This descriptive spectrum is not unusual. Another observes: 'I like it to be uplifting or relaxing depending on my mood. Music is very nostalgic too - brings up memories from growing up and so on' (R87). Other related words on the uplift end of this axis include escape (eight references), transport (four) and transcendent (two).

Some of the remarks about how popular music is uplifting include explicitly religious references. It is 'Uplifting and exciting, Spiritual and feeding of the soul' (R18), or, by contrast, 'Uplifting, 
cathartic, stirring, transformational, profoundly moving, entertaining, awe-inspiring,' whilst going on to comment, 'It is pure escape from the day job - spiritual from a non-spiritual person (if that is not contradictory)' (R148). It should be noted that 11 out of the 23 respondents who referred to 'uplift' self-identified as religious, and $12 \mathrm{did}$ not. There is therefore little evident difference here.

Various contributors speak of a journey, movement or transmigration. Examples include a list of words noting that music is: 'Contemplative, escape, cultural identity, stimulating' (R71; our emphasis); others that it involves 'Taking out of oneself' (R78) and it 'Takes you to another place' (R82). Another participant observes that popular music is: 'Escapist, moving, transcendental, a shared experience (at a gig)' (R147), whilst a fifth remarks that: 'It provides a sort of ecstasy, lifting me out of myself onto a different plane' (R193). There is a strong sense that the language of uplift is referring to a feeling of transcendence, although it is rarely linked with any explicitly religious or theological terms, or that transcendence is necessarily being used in a religious sense. This echoes to some extent the findings of Lynch in his empirical research with clubbers in so far as the religious links are not made explicit, though the difference from Lynch's findings is that the language of transcendence is used (Lynch 179).

It was not easy to see what the other end of this particular axis should be. Unlike the other three axes, the counter-balance to 'uplift' (entailing stretching, reaching, rising) could be equally being 'at rest' or descending (digging, seeking depth). There are only four overt references to the word 'deep'. Nevertheless, they are worth noting: 'At times the emotions touched are so deep that I can be reduced to tears' (R9); 'Romantic Deep Spiritual' (R48); 'Positive, uplifting, deep thoughts, reflection' (R90); and 'I prefer deep, meaningful music and lyrics' (R178). However, if the language of 'uplift' is used to infer or describe experiences of transcendence, then we can see that the language of depth is closely related to people's awareness of, and entry into, their inner lives. One participant comments that music: 'Reflects moods; calming, uplifting, stirring, makes me want to dance, thought provoking, memory enhancing, gives excitement, fun, promotes 
reflection, sadness.' The phrase 'promotes reflection' suggests looking into our inner depths and this is supported by the additional comment that: 'I feel that my life is grounded in music and that I am open and prepared to listen to many kinds of music e.g. from other cultures' (R75). Once again, the language of being 'grounded' in music is that of depth. Another analogy that employs depth is that of food. One participant writes about the effects of music as 'spiritual and feeding of the soul' (R18) whilst another about inspiration by saying that music changes 'my emotional state,' then adding: 'Music for me is food for my soul ... without music my life would be less rich ... music is a medium which I use to change my inner world but also brings me a sense of getting in touch with my innermost thoughts and feelings.' (R152)

There are other analogies and metaphors in our data which point in the direction of depth and immanence. Two contributors associate the word 'yearn' with music (Respondents 94 and 184), whilst another writes of how 'music is like a second heartbeat to me. I need to feel it, taste it, smell it, live it. Melodies and basslines and stories and words dictate my being - they can lift me or drown me' (R211). The language of depth is thus being expressed in the words of inner emotions (yearning), body (a second heartbeat) and physical experience (drowned). Another participant notes that music refers to their 'pivotal core' and is both' fundamental' and 'ineffable' (R189). Once again the underlying analogy of the 'core' speaks of immanence and inner depth. To claim that depth, and related imagery and terminology, represents a clear indication by our respondents of the other end of the axis to 'uplift' might seem like an imposition of our categories onto the data. The quality and intensity of the material just presented does carry significant weight. In keeping with the approach we are adopting to the data, however (and bearing in mind a quantitative dimension in our analysis of the qualitative data gathered), the other end of the 'uplift' axis is best represented by the word 'relax'. 'Relaxing', 'relaxes, 'relaxes', 'relaxed' or 'relaxation' are, alongside emotion/s or emotional, the most frequently offered words in the open questions of our survey (29 out of 231, 17 of whom self-identified as not religious). 
Though potentially allied with 'joy' and 'happiness' - to be considered shortly - and 'calm', which we shall use as a counter to 'energy' in due course, 'relax' and cognate words indicate for listeners the way in which music brings them to a safe place, a place of rest, in which creative, constructive, positive things can occur. Thus, in the words of some of the participants: 'It is relaxing and impassions me [sic]. Make(s) me want to make a positive difference to the world' (R37); 'Positive energy, uplifting, calming, energizing, relaxing' (R39); 'chilled-out stuff to relax to at bedtime, zone out of outside world (on headphones)' (R66). It is important to stress that relaxation is not here being thought of as a place of inactivity or thoughtlessness. It is being linked to a constructive activity, even when seen as escaping from the 'outside world'. Functioning in a similar way to the 'affective space' we have spoken about in our own earlier work (Marsh and Roberts Personal Jesus 16-21), the place of relaxation is a 'zone' where musicusers experience positive effects. As the opposite end of the axis from uplift it is, we might say, the locus for activity which can lead to uplift, whilst also offering the possibility of inner enquiry and depth. The fact that more self-identified non-religious than religious people use the term perhaps shows that cognitive or affective work being undertaken around the practice of musiclistening is more likely to happen for non-religious in relation to music, because religious people have different activities through which they 'relax' and feel safe.

(ii) Inspiration Memory

Sixteen respondents (only seven of whom were self-referred as religious) commented on the inspirational nature of popular music, although many of those that included this word did so without qualification or articulating their feelings about this experience (similar to the ways in which participants used the word 'relax'). Thus, remarks to the effect that music is 'Inspirational, joyful, moving, thought-providing' (R30), 'Inspiring, comforting' (R31), 'Relaxing, energizing, inspiring' (R32), 'Inspiring' (R44), 'Inspiration and relaxation' (R166) and 'Amazing thought- 
provoking, inspirational (R216) are not developed with further statements or analysis. We can speculate that words such as 'inspiration' and 'inspirational' may appear to be sufficiently descriptive to their users not to warrant any further clarification. Other words that can be plotted on this axis include moving (nine references), tingling (four references), beauty (three references), and wonder (one reference).

Exceptions included the contribution whose terms associated with popular music were: 'Uplifting, music is life, inspiring', and who went on to say: 'Music is the catalyst that can run a whole gamut of emotions. It has the ability to make me feel sad, make me happy, angry or feel totally uplifted. I could not imagine my world without music' (R73). Here the inspirational direction is upwards ('feel totally uplifted') and horizontal ('the catalyst that can run...') and a second respondent also wrote about inspiration in similar vertical and horizontal terms. Thus inspiration is vertical ('it provides a sort of ecstasy, lifting me out of myself onto a different plane') whilst also having an impact upon concrete, daily life: 'I often have instrumental music on in the background while I am working (reading and writing), although at these times I don't really listen to it - or even hear it - it is somehow inspirational as well as serving to cut out extraneous noise and focus my thoughts. I always have a disc of the moment, which I will play over and over for days or weeks before moving on to something else. Apart from this, I am becoming increasingly impatient of background music, preferring to listen without doing anything else. The exception to this is while driving or cycling, when the music occupies a different part of the brain' (R193).

When we place the four references to the tingle factor and three references to beauty on this axis, all of these words suggest we are in the social and psychological worlds of enchantment where the everyday and the mundane are transformed into something more significant. Charles Taylor notes the importance of the enchanted nature of the pre-Enlightened world and how the process of disenchantment played an important part in the emergence of secular ideas (Taylor 
25-26). Indeed, exploration of the themes of enchantment and re-enchantment have been a feature of recent sociological and religious studies work (Lyon, Partridge, Graham). There is a strong indication from this axis that a sense of enchantment still exists. One participant comments that 'music has to move me, otherwise I don't listen' and adds 'music is life. Without it, remove my ears. Tori Amos saved my life. Depeche Mode shaped my life' (R215). Another states that music 'refreshes parts that other media' including the other arts fail to reach and that a key aspect in that process is the 'tingle factor' (R6). A further respondent associates music with the 'release of tension, unclutters the mind, light, floaty, happy, distraction, escapism, forget the world' (R179). We shall discuss some of those terms further below but the sensations of floating, escaping and forgetting the world all point to the enchanting nature of music. They function as cognates of inspiration in so far as they indicate that music-users have a sense of being given something, or being released in order to receive. Or, at the very least, they are enabled through their listening to use the music to see things differently, to see things in a new light. It is worth noting at this point that the relationships between specific musicians and their audiences is an area ripe for further exploration. We have undertaken some preliminary enquiries in this field (Marsh and Roberts Soundtracks; Personal Jesus 134-5, 171-2).

At the other end of the axis is the function of memory and recollection. There are fourteen direct references to memory in our data (only five of which come from self-identified religious respondents), plus seven citations of 'nostalgia' which might also be included under this heading. Three use a very similar phrase when they state that popular music 'brings back/up memories' (R24, R50 and R87). Others associate music with 'relaxing, reminiscing, memories' (R136) or that 'one of the greatest feelings ever is listening to albums that I have strong memories behind especially stuff that I grew up with' (R213). Three referred to music providing the 'soundtrack to life' (R86, R182 and R194) and others made similar comments without employing that analogy, e.g. 'music often marks and becomes associated with events in my life' (R26) and 'music is like a journal of my life' (R54). In other words, music becomes a crucial element in people's personal 
identity and their life story. As another remarks, music is 'evocative' and 'songs will take you back to the time you first/most memorably heard them' (R77).

Our data suggests that links between popular music and identity extend beyond the personal (in the sense of 'individual'). Although not highly developed, there are references to cultural identity too. The ideas and words that one participant associated with music included: 'contemplative, escape, cultural identity, stimulating' (R71 - our italics) whilst another connected it to 'things like social commentary, Englishness, nostalgia' (R190 - our italics). This is not surprising given that 'music is very nostalgic too - brings up memories from growing up and so on' (R87).

However, a discordant note is sounded by one contributor who openly admits that music had played an important part in developing his sense of self but that it no longer did: 'Music was hugely important to me as a teenager and to some extent in my early twenties - it was mostly to do with developing my identity and also as escapism. But as I'm getting older (mid-thirties now), it's not important at all, and in fact I have very little time to dedicate to it' (R138). It would be fascinating to know whether anything had replaced music in his later years and what (if anything) was now performing the function for his identity that music had done in the past. Another criticized our question asking for each individual's favourite piece of music and those contributors who could make such a choice, writing that there was 'literally not a chance' of answering and 'if your respondants [sic] are able to do this I wonder if they like music enough!' (R72). This person had a very clear understanding of the identity of any self-respecting music fan.

(iii) Energy <------------> Calm

Our third axis plots the descriptors used by respondents to convey the energy and the sense of calm imbued by popular music. 'Energy' is used by twelve respondents but is implied by many other terms used. Words such as moving (R30); impassioned (R37); peppy and pumped-up 
(R40); upbeat and wild (R45); and galvanising (R83) imply energy, as do phrases such as: 'makes me want to dance' (R75); 'it motivates me to take part in activities I wouldn't otherwise want to do (i.e. fitness)' (R92); and 'recharging my batteries' (R171). It might also be implied in a statement such as: 'Make(s) me want to make a positive difference to the world' (R37). For our contributors energy seems particularly to lie in the interplay between mood and embodied action. For instance, one who uses this term observes that: 'I use music to alter/augment my mood, e.g. if I'm having a bad day, "angry" music i.e. rock, Indy music, get the frustrations out my system, whilst if I've a deadline (I also run my own business from home) fast dance music speeds my mental processes up whilst soft music is good for romantic dinners (most nights to be honest) etc.' (R175). In a similar vein, another respondent notes: 'Music helps in all moods. It relaxes or energises. It can transport me into a world of my own or it's something I can share with others in my living room or with thousands of others at a festival. Loud music has a physicality to it too that [is] not found elsewhere, yet I often use music to go to sleep to' (R147). The physical aspect of listening to popular music is also picked up in a number of other embodied references. One participant references its 'visceral' nature and observes the contrast with his partner's being 'more thoughtful and drawn to the lyrics' whereas 'I am more moved by the music and rhythm' (R53). There are also two mentions of the orgasmic nature of music including the rather remarkable claim that: 'AC/DC gave me an orgasm without physical contact' (R207).

Another participant places her musical use on an axis between calm and energetic when she describes it as depending 'on why I'm listening to it. Can be calming, energising, happy-making, distracting focussing'. She continues: 'What I like to listen to will depend on whether it's just me on my own, whether I want to cheer myself up, whether I want something more intense, whether I want to listen with others, whether I want to dance to it, whether it sits in the background, whether I want to sing along. Sometimes I want to listen to one piece over and over again, other times I need a mix of things' (R202). By contrast, one respondent describes how 
their physical state shapes their use of music: 'my anankastic personality disorder happily creates my music schedule for me' (R188).

Strikingly, only two of the twelve users of the term 'energy' self-identify as religious. This may mean that religious music-users are less likely to use music for explicit purposes of celebrating embodiment (e.g., dance, exercise or sport), or are less self-consciously energetic individuals! The word 'calm' is used by thirteen participants (six religious, seven not) and we distinguish this from 'relax' (used above) by noting that the process of calming involves moving from a state of some anxiety to a sense of peace, whereas relaxation implies a starting point that is less fraught. On this axis we also include the four references to soothing, three to "release of stress/tension" (R92, R169 and R179) and two references to contentment (R161 and R184) which also imply an active change of mood. A good example of calm/calming being used in this way is the observation: 'I put on music to either reflect my mood or to change it, e.g. upbeat showtunes to bring me out of a bad mood, or classical music if I'm stressed out to calm me down' (R199). A similar psychological change is observed in the description of the effects of popular music as 'profound, exhilarated, worked up into a state of anger or frustration, calming. Above all, my emotional experience of music is cathartic' (R154).

On this axis a number of people have reflected upon their choice of what music they listen to and when, for example: 'Always on in the car, use rock music to run to or in the gym. I like to relax to chilled music in the conservatory. I like instrumental music as background whilst working and writing' (R149). However, another is less active in her use and choices of music, stating: 'I enjoy music especially when it puts you in a good mood - calming effect' and then continues: 'I appreciate music more especially as I’ve got older. I never think to put music on when I'm on my own (unless I'm revising when I put classical music on) but when someone else has music on I really enjoy listening to it' (R177).

(iv) Joy, Happiness <-------------> Sad, sadness 
Our final axis involves first the two most frequently emotions recorded by our participants happiness (happy, happier) (27) and joy (joyful, enjoy, enjoyment) (24), and their opposite pole sad/sadness (mentioned by 13). Typical of the quotations at the positive end of this axis are statements such as: 'I just love music, it keeps me smiling and happy ... I get emotional listening to people sing or listening to music' (R226). Others speak of 'physical and emotional enjoyment' (R183), or group positive emotions together, as in 'joyful, uplifting, happy, brilliant' (R72).

Striking on this axis is a distinction between religious and non-religious respondents. Only eleven of the twenty-seven referring to happy/happiness are religious, whereas religious respondents recorded fifteen of the twenty-four joy/joyful responses. This suggests a difference in the linguistic background (cognitive framework) against which religious and non-religious musicusers report their positive emotions.

In addition to the fifty-one references to joy and happiness, there are also five citations of comfort, four of reflection/reflective and two of contemplation. These could, of course, be located at a number of points on our various axes. We mention them here simply because the contrast between the two ends of the axis in this case (joy v sadness) is especially marked and creates a space where deep emotions are experienced and reflected upon.

The citations of popular music being helpful for reflection include the associations that it 'can make me upbeat, wild, or reflective depending on what's playing' (R45); it 'reflects moods; calming, uplifting, stirring, makes me want to dance, thought provoking, memory enhancing, gives excitement, fun, promotes reflection, sadness' (R75); it is 'positive, uplifting, deep thoughts, reflection' (R90); and the statement that 'I often listen to music when I'm in a reflective mood. Nostalgia. Excitement. Romantic. Therapeutic' (R191). We noted only one direct reference to prayer, from a religious respondent who connected listening to music with the 'spiritual and feeding of the soul, prayerful and abiding in love' (R18). 
With respect to sad/sadness, it is striking that most references are also juxtaposed with positive terms. Respondents did not record sadness in isolation but highlighted the fact that music accompanies their experience of a range (and even extremes) of emotion. Hence, responses such as: 'Happy sad moved' (R41); 'Relaxing energizing joy sadness' (R52) or 'It has the ability to make me feel sad, make me happy, angry or feel totally uplifted' (R73) are typical of those who spoke of sadness.

The four intersecting axes which emerge from our data and frame our respondents' sense of mood and experience of emotions as set in figure 1 are, of course, open to further analysis and development. It would also be worth exploring further the striking similarities and few differences between our research and findings from musicological research undertaken by Juslin and Laukka (reported in Sloboda, Music in Everyday Life). In the remainder of this article, our simple purpose is to 'read' the evidence in relation to contemporary discussions about spirituality and religion. Our task is to ask whether the social imaginary we have constructed from the empirical data gathered may offer a framework in and through which contemporary reflections on developments in spirituality become possible. The social imaginary may not be able to function as a contemporary spirituality of Western (mostly popular Western) music, but it is at least suggestive of one.

\section{The Acoustic Axes as a Social imaginary: A Spirituality of Music?}

In the analysis of our quantitative data for the earlier paper we drew attention to the independent yet linked observations of Robert N. Bellah and Iain McGilchrist which see rhythm and music as the basis of human sociality (Bellah 127-8, McGilchrist 104; Marsh and Roberts Habits). With the analysis of our qualitative data the social function of music has once again been at the forefront of respondents' comments, though there is no space in this present article fully to explore the evidence of the extent to which and ways in which music-listeners connect with others in what 
they choose to listen to, and the contexts in which they listen (in particular, in the company of friends). In presenting the four acoustic axes above, however, we have been able to plot the descriptors and experiences that participants have shared. We can now take those four axes a stage further and transpose them onto a different framework to map how they inform and shape the social imaginary of people who listen to such music. At this point, categories from the study of religion and spirituality become significant in so far as they inform the individual and social practices which people are engaged in as they consume music. Reflecting our original pattern, it is possible to offer four axes based on the data from our questionnaires:

(i) Transcendence $<---------->>$ Immanence

(ii) Enchantment <-----------> Identity

(iii) Embodiment $<------------>$ Self-acceptance

(iv) $\quad$ Ecstasy <-----------> Reflectiveness

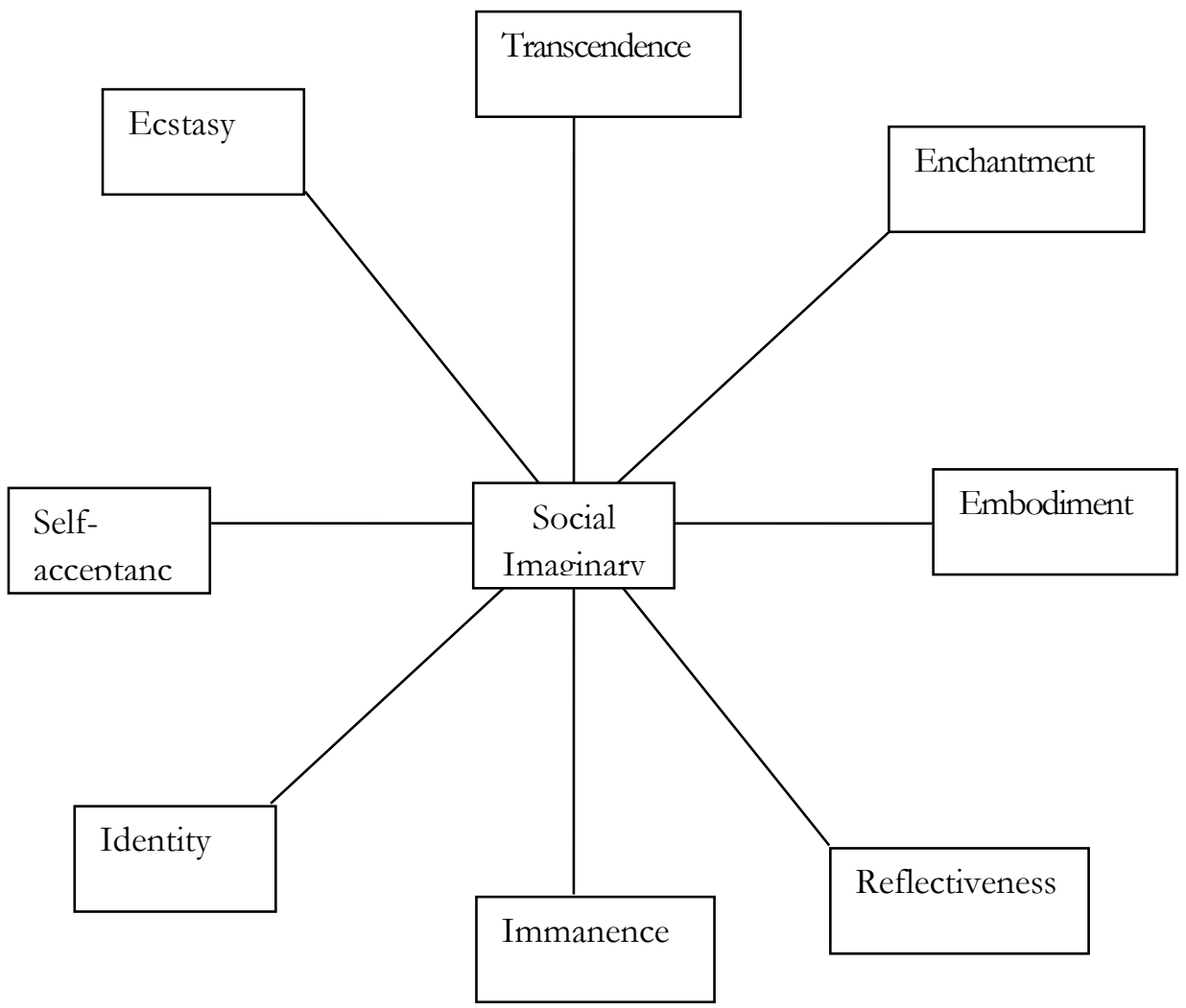

Figure 2 Acoustic Axes as a musical-spiritual social imaginary 
This mapping of the correlations between spirituality-related terms and those offered by musicusers in the qualitative data supplied does not, of course, constitute a perfect 'fit'. We are merely seeking here to highlight important points of contact which enable the lens of one discipline's reading of human practice to be used in informing how self-presentation by users of music may be understood.

The five correlations which fit easily together are joy/happiness and ecstasy, uplift and transcendence, inspiration and enchantment, memory and identity and calm and self-acceptance. Less direct are the correlations between energy and embodiment, relax/ation and immanence and sad/ness and reflectiveness. Nevertheless each is worth exploring, in order to clarify the shape of the spirituality of music which emerges.

Ecstasy is an established category in the study of religion. If anything, notes of 'joy' and 'happiness' may underplay the sense of fulfilment that listeners experience, even though a limited number of respondents do use the term 'ecstasy' explicitly. We are here observing not merely the positive effects of music, but the extent of those positive feelings. Uplift/transcendence indicates how such positivity comes about. The sense of 'being transported', or lifted out, of one's mundane experience (and even beyond one's body, even if this is only a turn of phrase) signals how it is felt that the sense of the euphoric occurs. The involuntary element here (this cannot be controlled) is implied in those respondents who used the term 'inspire'. While this element of inspiration (being given a gift from outside oneself) finds its echo in the notion on enchantment, it could be argued that contemporary explorations of dis-/re-/enchantment do highlight the ambiguity as to whether we are dealing here with something contained within the practice of music and listening, or whether enchantment is (merely) an interpretative lens through which music in being given meaning.

Memory is easily correlated with identity, though admittedly requires no specifically religious reading to take effect. The common bond here is narrative - the life narratives that we all make 
in constructing and expressing our personal identities (our 'selves'). Crucial here, though, is the role that music plays in the way it plots points in that life narrative, how it ensures an affective thread through the story plotted, and the extent to which a life narrative can therefore take account of life's extremes (of happiness and sadness).

Sadness and reflectivity are not to be linked exclusively - for reflectiveness is provoked by the act of undertaking any cognitive work on one's music-listening experiences. It was, however, striking that a significant number of respondents emphasized the way in which music helped them to face their sadness.

Calm and self-acceptance sit easily together, relax/ation and immanence less so. Music can nevertheless put people into a safe, secure place. If relaxation sounds too comfortable, then immanence does more to suggest that in the context of a safe space, music permits a person to be at ease. It can be argued - in keeping with insights about what religious practice at its best achieves - that it is through stepping outside of oneself (into a transcendent world, or at least into a narrative or practice of transcendence) that it is possible to recognise who one is. Immanence and self-acceptance are the corollaries of the calm and relaxed world which music can create.

The place of repose stands opposite the energy of embodiment, where the frenzy of dance can signify an unexpected, and potentially uncontrollable, element of what music might do to one's body. Opening oneself up to music entails risk. Our respondents clearly liked being (largely) in control of what they listened to. But there is sufficient evidence too of recognising that one might not be wholly in control of one's body, or of what music might do.

Taylor argues that art and music not only play a vital role in the creation of individual and collective social imaginaries but that they have always been linked with the 'special register' of the ontic experiences of worship and liturgy (Taylor 354). In pre-Enlightenment social imaginaries, 'even telling a story within certain canonical forms, singing a love song, can be understood in this earlier "ontic" way. It lifts the events to a higher plane; there is now something archetypical, 
something close to the universal human grain, in this love, or this story. It places them in a higher register' (ibid.). As social imaginaries became disembedded from theological and religious world views, becoming more fragmented in the process, one of the ways in which integration could be maintained was by locating it in personal experience. Taylor cites poetry as an example of where the relocation of the social imaginary might occur (Taylor 408-409). In contemporary Western society, we are arguing, like poetry, music articulates the fragmentation and shapes a coherent world, locating the basis for social imaginaries in 'inner, individual experience, in personalized meaning' (ibid.). In this respect, music creates a social imaginary which functions as religions have in the past (and still do for many) and it is therefore not unreasonable to speak of the 'spirituality of music', constituted by the axes we have identified and described.

One of the dangers of Taylor's concept of 'social imaginary', admittedly, is the impression it creates that at stake is the human creation of a world with the mind and the intellect. Embodiment, however, remains essential, and our example of music spells this out clearly. As Mark Johnson writes, "understanding is the way we "have a world," the way we experience our world as a comprehensive reality. Such understanding, therefore, involves our whole being - our bodily capacities and skills, our values, our moods and attitudes, our entire cultural tradition, the way in which we are bound up with a linguistic community, our aesthetic sensibilities, and so forth' Johnson 102, cf. DeNora's observation that 'Music is, or rather can serve as, a constitutive property of bodily being' DeNora 99). This is very evident in our respondents' contributions.

All this being so, it is clear that the bodily and psycho-social experience which is 'listening to music' can be seen to function in the way that liturgies do for those who explicitly inhabit religious frameworks. Those listeners who commit themselves in a disciplined way to the consumption of music (and it is clear that a great many of our respondents wanted to communicate how much music meant to them) use music in order to deal existentially with the emotions and facets of human experience identified in our four acoustic axes. In this limited, yet 
evident, sense, music is their spirituality, if by 'spirituality' we mean 'meaningful life structure' or 'set of life-shaping practices.'

A Christian theologian who has employed Taylor's concept of the social imaginary is William A. Dyrness. He argues that a group's imaginary or 'interpretive situation' is 'embodied not in ideas but in images, stories, and sets of practices; it is carried by actors who already know what they do and tacitly agree on what the practices are' (Dyrness 75-76). Drawing upon the example of popular music and popular arts more generally, he goes on to argue that: 'since symbolic practices are fundamental to human flourishing, any project of human betterment will seek to appreciate and celebrate the aesthetic impulse that is already present in the community' (Dyrness 254). In other words, the social practices of listening to popular music share striking common ground with other social practices such as religion, a point made explicit in North and Hargreaves observations about the common ground between 'problem music' and religious controversies (North and Hargreaves 2008 205-6).

Dyrness is surely right, though our point is in no way to claim that listening to music, popular or otherwise, confirms or relates to a particular religious or theological tradition. Nor, indeed, do we want to claim a universality in music which can be distilled to something resembling a universal spirituality. Musicologists' work on the sheer diversity of forms of music would certainly not permit such a conclusion to be drawn too hastily. Our proposal is much more modest. We suggest that the mapping exercise we have been able to undertake on the basis of the empirical data gathered shows how music is used in a life-affirming, life-shaping way. There is no such thing as 'just listening'. People use music. In so doing it connects with the social imaginary in which they participate, whether consciously or not. The more explicit the reflective engagement with the practice of listening becomes, however (and we suspect that our interaction as researchers with those who responded to our questionnaire enhanced that reflective process for some), the more structured (and 'spirituality like') the engagement with and use of music becomes. Such a 'spirituality of music' falls, however, considerably short of any structured belief 
system or 'theology.' As we have shown elsewhere, unlike the stories prominent in popular film, narratives of redemption are in short supply in the way that popular music is consumed (Personal Jesus 146-155, esp. 154). This may echo the concerns of Carrette and King about 'cultural prozac' (cited in MacKian 42). Nevertheless, although spirituality is a vague and perhaps unhelpful term (though more culturally acceptable than 'religion' in the West), and when religion itself is, too easily and not altogether accurately, viewed as declining, it is vital that such a practice as music consumption is identified as a locus where religion-like, meaning-making configurations are in the process of being constructed, however oriented towards feelgood factors it may be. Without that endeavour - both scholarly and cultural-practical - we shall be in danger of missing the point of Taylor's analysis, and failing to recognise the ethical imperatives which are needed in relation to the groups we form and the cultural habits we have. They matter decisively, even when not labelled 'religious.' Whether or not religious insights and conceptualities will be needed in the long-term to assist in re-working the vocabulary which aids human flourishing, the interplay between the explicitly religious and the many social practices through which people make meaning will still need to be explored.

Clive Marsh is Director of the Vaughan Centre for Lifelong Learning, University of Leicester. Vaughan S. Roberts is Vicar of the Collegiate Church of St Mary and Team Rector of Warwick. The authors' latest co-written book is: Personal Jesus: How Popular Music Shapes Our Souls (Grand Rapids: Baker Academic 2012). CORRESPONDENCE: Dr. Clive Marsh, Vaughan Centre for Lifelong Learning, University of Leicester, UK; Revd. Dr. Vaughan S Roberts, Collegiate Church of St Mary, Warwick, UK. 
References

Bellah, Robert N. Religion in Human Evolution: from the Paleolithic to the Axial Age. Cambridge, MA \& London: The Belknap Press, 2011.

DeNora, Tia. Music in Everyday Life. Cambridge \& New York: Cambridge University Press 2000.

Dyrness, William A. Poetic Theology: God and the Poetics of Everyday Life. Grand Rapids, Michigan \& Cambridge, UK: William B Eerdmans, 2011.

Gill, Robin. Theology Shaped by Society: Sociological Theology Volume 2. Farnham and Burlington, VT: Ashgate 2012.

Graham, Gordon. The Re-enchantment of the World: Art versus Religion. Oxford: Oxford University Press 2010.

Johnson, Mark. The Body in the Mind: The Bodily Basis of Meaning, Imagination, and Reason. Chicago \& London: The University of Chicago Press, 1987.

Juslin, Patrik and John Sloboda, eds. Music and Emotion: Theory and Research. Oxford: Oxford University Press 2001.

Juslin, Patrik and John Sloboda, eds. Handbook of Music and Emotion: Theory, Research, Applications. Oxford: Oxford University Press 2011.

Lakoff, George. Women, Fire, and Dangerous Things: What Categories Reveal about the Mind. Chicago \& London: The University of Chicago Press, 1987.

Levitin, Daniel. The World in Six Songs: How the Musical Brain Created Human Nature (updated edition). London: Aurum Press, 2010.

Lyon, David. Jesus in Disneyland: Religion in Postmodern Times. Oxford: Polity Press 2000.

McGilchrist, Iain. The Master and his Emissary: The Divided Brain and the Making of the Western World. New Haven \& London: Yale University Press, 2009.

MacKian, Sara. Everyday Spirituality: Social and Spatial Worlds of Enchantment. Basingstoke and New York: Palgrave Macmillan, 2012. 
Marsh, Clive and Vaughan S. Roberts. 'Soundtracks of Acrobatic Selves: Fan-Site Religion in the Reception and Use of the Music of U2', Journal of Contemporary Religion 26 (2011): 419-432.

Marsh, Clive and Vaughan S. Roberts. Personal Jesus: How Popular Music Shapes Our Souls. Grand Rapids: Baker Academic Press, 2012.

Marsh, Clive and Vaughan S. Roberts. 'Listening as Religious Practice (Part One) - Quantitative

Data from an Empirical Study of the Cultural Habits Music Fans’ [... 2014]

North, Adrian and Hargreaves, David. The Social and Applied Psychology of Music. Oxford \& New York: Oxford University Press, 2008.

Partridge, Christopher. The Re-enchantment of the West Vol.1. London and New York: T \& T Clark 2004.

Partridge, Christopher. The Re-enchantment of the West Vol.2. London and New York: T \& T Clark 2006.

Robinson, Jenefer. 'The Emotions in Art.' Ed. Peter Kivy. The Blackwell Guide to Aesthetics. Oxford and Malden, MA: Wiley-Blackwell 2003. 174-192.

---., Deeper than Reason: Emotion and its Role in Literature, Music, and Art. Oxford: Clarendon Press 2005.

Sloboda, John. 'Music in Everyday Life: The Role of Emotions.' Eds. Patrik Juslin and John Sloboda. Handbook of Music and Emotion: Theory, Research, Applications. Oxford: Oxford University Press 2011. 493-514.

Taylor, Charles. A Secular Age, Cambridge: MA \& London, UK: Belknap Press, 2007. 